\title{
El jardín como elemento integrador del hombre en la metrópoli
}

\section{Gardens as an integrating element of human beings in the metropolis}

\author{
Esperanza Macarena Ruiz Gómez \\ Universidad Complutense de Madrid. Facultad de Bellas Artes. \\ Departamento de Pintura y Restauración. \\ emruiz@pdi.ucm.es
}

Recibido: 21 de septiembre de 2010

Aprobado: 6 de abril de 2011

\section{Resumen}

Estamos en un momento en el que el paisaje y los jardines estimulan al hombre en todos los campos del saber. El paisaje depende de la existencia del ser humano, pues éste es el receptor de los elementos tanto naturales como artificiales que lo constituyen, además es un concepto que da sentido a nuestro entorno y nuestra relación con el mismo.

En relación con el urbanismo actual, las "zonas verdes" han proliferado y desplazado peligrosamente a los jardines tradicionales, pues como explicaremos más adelante, nos son lo mismo ni cumplen las mismas funciones. Aunque estos espacios verdes son considerados por la Organización Mundial de la Salud indispensables en las ciudades, en muchas ocasiones son construidos únicamente bajo el prisma de la especulación urbanística, dejando a un lado su interrelación con el entorno natural y cultural.

Palabras Clave: Jardín, Paisaje, Zonas verdes.

Ruiz Gómez, E. M. 2012: El jardín como elemento integrador del hombre en la metrópoli. Arte, Individuo y Sociedad, 24(1), 147-157

\begin{abstract}
Nowadays, landscapes and gardens are able to stimulate people in every field of knowledge. Landscape depends on human being's existence, as they are the recipients of both the natural and artificial elements that constitute them. It's also a concept that gives meaning to our environment and our relationship with it.

In relation to actual urbanism, "green spaces" have spread and replaced traditional gardens, as we will explain later, these are not the same and don't fulfil the same functions. Although the World Health Organization considered these green spaces as essential and necessary in cities, on many occasions they are built under urbanistic speculation's perspective, ignoring its relationship with their natural and cultural environment.
\end{abstract}

Key Words: Garden, Landscape, Green spaces.

Ruiz Gómez , E. M. 2012: Gardens as an integrating element of human beings in the metropolis. Arte, Individuo y Sociedad, 24(1), 147-157

Sumario: 1. Introducción, 2. Idea de Paisaje, 3. Idea de jardín, 4. Espacios Verdes, 5. Jardines y zonas verdes en el siglo XXI. 6. Jardines - Espacios verdes, 7.Conclusiones. Referencias 


\section{Introducción}

Actualmente hay un apogeo con todo lo relacionado con el paisaje, los jardines y en especial con las denominadas zonas verdes y parques, ya que son sinónimo de bienestar, prosperidad y calidad de vida, por ello, hay un importante incremento en la incorporación de estos espacios en las grandes urbes.

Esta creación de espacios verdes, ajardinados y de disfrute en las grandes poblaciones, podemos decir que empezó a finales del siglo XVIII durante la Revolución Industrial, pero es a finales del siglo XX y comienzos del XXI cuando se produce un auge de estos espacios debido a que gran parte de la población vive en zonas urbanas, pero aunque son elementos del entorno natural creados para el disfrute de los ciudadanos y la mejora de la calidad de vida, en ningún momento debemos confundir estos "espacios verdes" con la idea de "jardín".

Por ello, en este texto hablaremos de la diferencia existente entre espacio verde y jardín, y de la gran importancia de la relación hombre-jardín-paisaje tanto en nuestros días como en épocas pasadas.

Al ser el hilo conductor de este tex to el binomio jardín - zona verde como elementos importantes en la estructura de las ciudades del siglo XXI, expondré de forma somera a modo de antecedentes qué entendemos por paisaje, jardín y espacios verdes, pues son conceptos importantes que creo necesario desarrollar.

\section{Idea de Paisaje}

La UNESCO en 1972 incorporó como patrimonio de la humanidad el concepto de paisaje teniendo en cuenta las relaciones entre los componentes naturales y culturales a lo largo del tiempo en los lugares. 1

Posteriormente, en octubre del 2000, La Convención Europea del Paisaje firmó en Florencia El Convenio Europeo del Paisaje, que después fue ratificado por el Estado Español:

[...] se compromete a reconocer jurídicamente los paisajes como elementos fundamentales del entorno humano, expresión de la diversidad de su patrimonio común, cultural y natural, y como fundamento de su identidad. (Convenio Europeo del Paisaje. 2000, Art. 5).

Si tuviéramos que hacer una definición de paisaje, en esencia diríamos que el paisaje es un concepto inventado por el ser humano y que surge después de la observación por el hombre de un terreno o territorio. Dependiendo de la rama del saber, este término puede tener connotaciones diferentes, pero siempre hay en común la necesidad de un sujeto observador, que es el que da sentido a la existencia del paisaje.

El paisaje nos proporciona: 


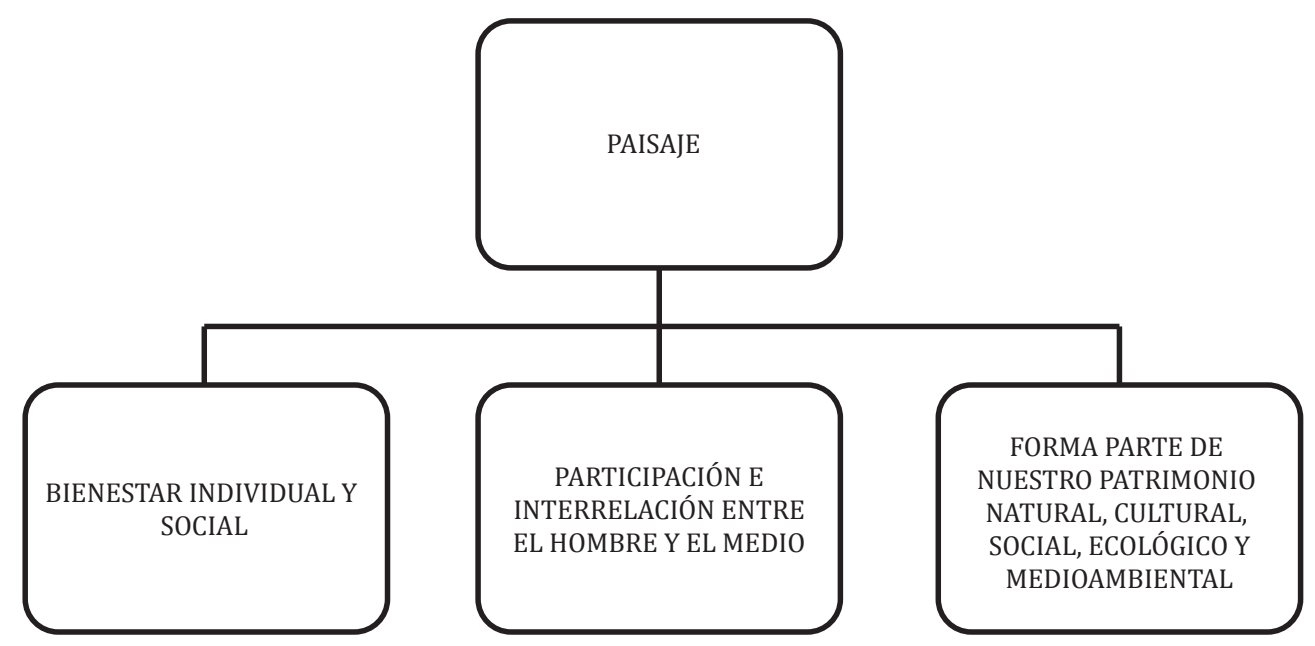

\section{Idea de jardín}

Si la idea de paisaje es un componente cultura importante en la historia del hombre, no lo es menos el concepto de jardín, pues ya en las construcciones de las primeras ciudades, el ser humano ha dedicado espacios para la creación de jardines y parques, en algunas ocasiones como lugares de entretenimiento y de decoración y en otras, con connotaciones de carácter cosmogónico que aludían entre otras muchos aspectos a la relación del hombre con su entorno natural.

Es importante tener claro que el jardín es un elemento natural siempre modelado y delimitado por la mano del hombre, y ha sido utilizado con frecuencia como espacio de expresión para mostrar la vinculación del hombre con su entorno natural. En palabras de Carmen Añón Feliú, Presidenta del Comité Científico Internacional de Jardines Históricos y Parques Culturales: “[...] los jardines son el reflejo de la cultura y tradición de un pueblo, en cuyo estudio confluye una serie de disciplinas, como la Filosofía, la Historia, la Literatura, la Botánica, la Simbología, el Arte, la Geología, etc."

En cuanto al significado etimológico, el vocablo jardín existe desde el siglo XII y viene del francés jart -gard que quiere decir huerto, vallado y gart en alemán que significa corro o círculo y del inglés yard cuyo significado es patio. Estas acepciones nos llevan siempre a la idea de un espacio delimitado.

El jardín nos proporciona: 


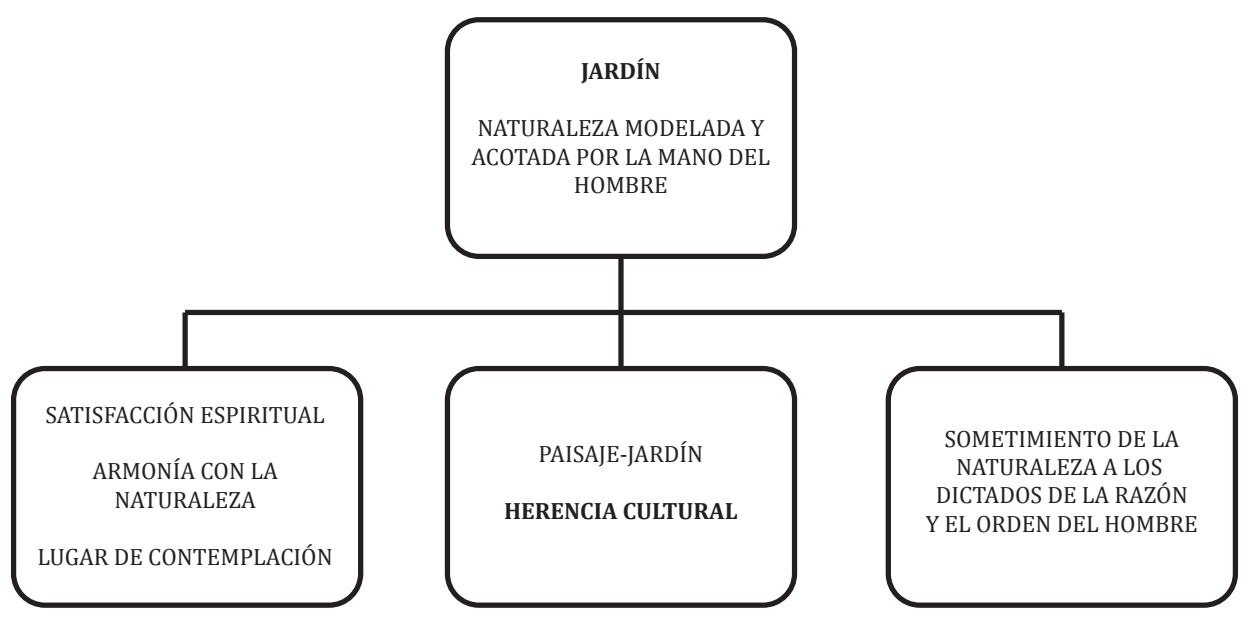

Al hablar del jardín, inevitablemente nos viene a la mente la idea del Paraíso, pues nos hace evocar un lugar tranquilo rodeado de naturaleza. El término paraíso viene del antiguo persa y significa espacio o jardín cerrado y de recreo. La historia del jardín forma una parte muy importante de la historia del paisaje, pero realmente la conciencia de otorgar a un jardín valor de patrimonio es muy reciente.

Haremos especial referencia a los jardines históricos, pues son de suma importancia dentro del patrimonio de una ciudad y su cuidado debe potenciarse para evitar el deterioro de estos y con ello perder su importante legado cultural, por ello citaremos la Carta de Florencia (ICOMOS-IFLA, 1981)2 en la que se definen ideas esenciales que hacen referencia a estos jardines:

Artículo 1. Un jardín histórico es una composición arquitectónica y vegetal que, desde el punto de vista de la historia o del arte, presenta un interés público. Como tal está considerado un monumento.

Artículo 2. El jardín histórico es una composición de arquitectura cuyo material es esencialmente vegetal y, por lo tanto, vivo, perecedero y renovable.

Artículo 3. Dado que es un monumento, el jardín histórico debe estar protegido según el espiritu de la Carta de Venecia. No obstante, en tanto en cuanto se trata de un monumento vivo, su protección se atiene a las reglas especificas, que son objeto de la presente Carta.

Artículo 4. Determinan la composición arquitectónica de un jardín histórico:

- su trazado y los diferentes perfiles del terreno.

- sus masas vegetales: especies, volúmenes, juegos de colores, distancias, alturas respectivas.

- sus elementos constructivos o decorativos.

- las aguas en movimiento o en reposo, el reflejo del cielo.

Artículo 5. Expresión de lazos estrechos entre la civilización y la naturaleza, lugar de deleite, propicio a la meditación o al ensueño, el jardín adquiere el sentido cósmico de 
una imagen idealizada del mundo un "paraiso" en el sentido etimológico del término, pero que da testimonio de una cultura, de un estilo, de una época y, en ocasiones, de la originalidad de un creador artístico.

\section{Espacios Verdes}

El origen social de estas zonas lo podemos encontrar en el s. XVIII con la creación de los primeros jardines públicos, realizados para cumplir principalmente la función de espacios de recreo para la creciente población, además de convertir el ambiente de la ciudad en más saludable, pues se llevó a cabo un movimiento higienista que trató de llevar agua potable, arbolado y sistema de alcantarillado a estos jardines. Si bien, es necesario especificar que, ya en la Antigua Grecia hallamos referencias de zonas de naturaleza destinadas al uso público y en la Antigua Roma junto a las grandes villas ajardinadas también se encontraban espacios para el recreo público como las termas, que poseían zonas de jardines que propiciaban la tertulia entre los ciudadanos.

Con el paso de los siglos, la población que habita en las ciudades ha ido aumentando vertiginosamente por lo que las grandes urbes además de contar con los jardines ya existentes, han tenido la necesidad de crear los denominados "espacios verdes" herederos de funciones de los jardines públicos y cuyas aportaciones más importantes a la vida del hombre son las de proporcionar una mejora en la calidad de vida y facilitar espacios de actividades culturales y lúdicas.

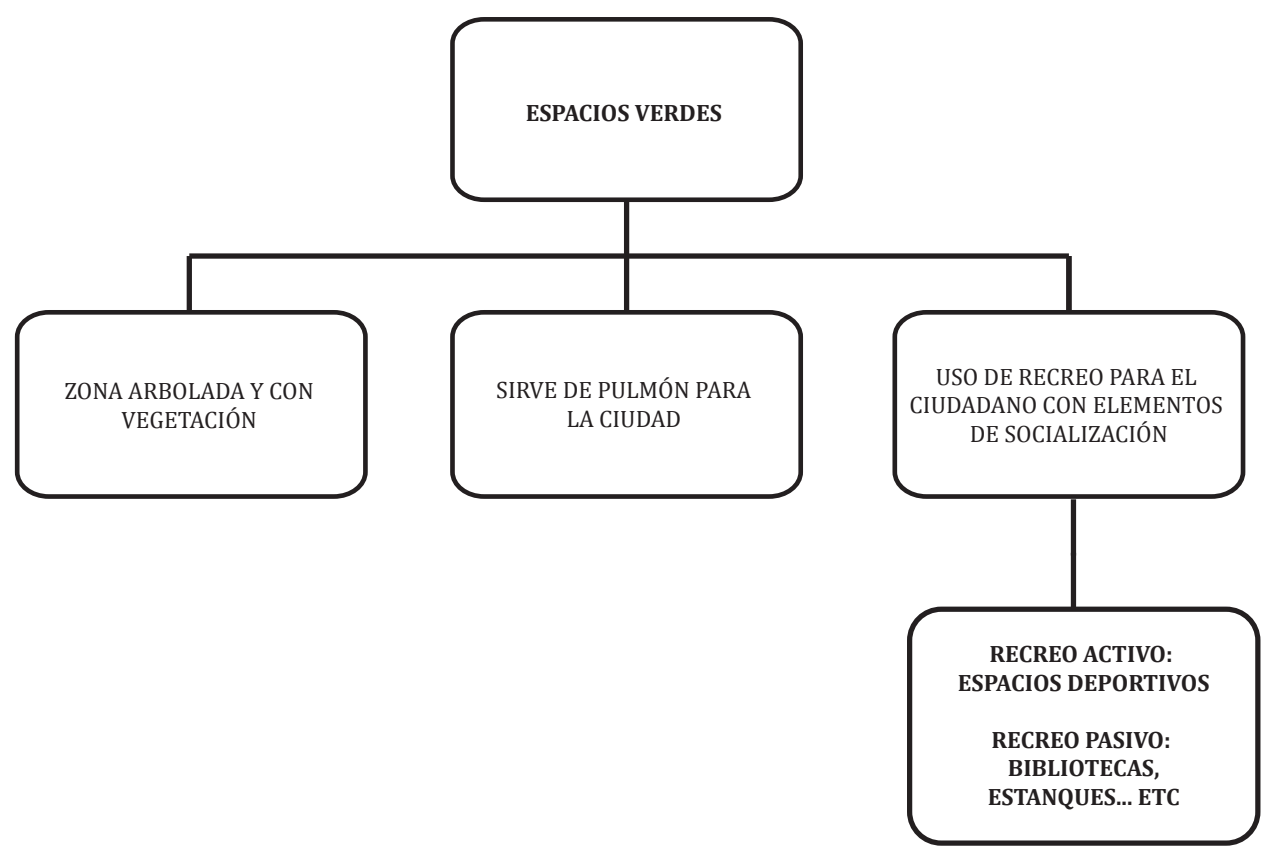




\section{Jardines y zonas verdes en el siglo XXI}

La fisonomía que poseen las grandes ciudades, podemos decir que es el resultado de complejos procesos en los que intervienen factores como pueden ser las oscilaciones demográficas, los cambios culturales, tecnológicos y económicos.

Como hemos citado con anterioridad, en Europa a partir de la Revolución Industrial comenzó un período de urbanismo que generó la necesidad de espacios abiertos, parques, jardines y zonas verdes para alejar al ciudadano del ajetreo urbano, mejorando con ello su calidad de vida, pues les aporta armonía, sosiego y salud mental.

Actualmente, parte importante de la estética de las urbes del s. XXI lo conforman entre otros, los jardines y zonas verdes. En nuestros días el "arte de los jardines" está presente en la mayoría de las grandes ciudades del mundo, pues ha dejado de ser considerado como un mero trabajo de artesanía.

Ciudades punteras a nivel mundial como Tokio y de culto milenario hacia los jardines 3 han integrado entre los grandes muros de sus gigantescos edificios construidos en estos últimos años con materiales como el acero, el cemento o el vidrio, exquisitos espacios ajardinados en donde fluye el agua, se respira la armonía y se descansa espiritualmente, indicándonos que además de no haberse olvidado en absoluto de su herencia cultural, manteniendo con ello un afortunado equilibrio entre modernidad y tradición, potencian la creación de estos espacios como elementos oxigenadores de la ciudad y de quienes viven en ella. Entre otros, hablaremos del jardín de Hama-rikyu que cuenta con una extensión de 8,7 hectáreas es un ejemplo de creación artística en donde se ha intentado reproducir en un reducido espacio los paisajes naturales japoneses. Situado cerca de la bahía de Tokio, fue construido en el siglo XVII por la familia Tokugawa y en la primera mitad del siglo XX fue donado a la ciudad de Tokio y ha sido ampliado manteniendo en todo lo posible la esencia de su diseño originario.

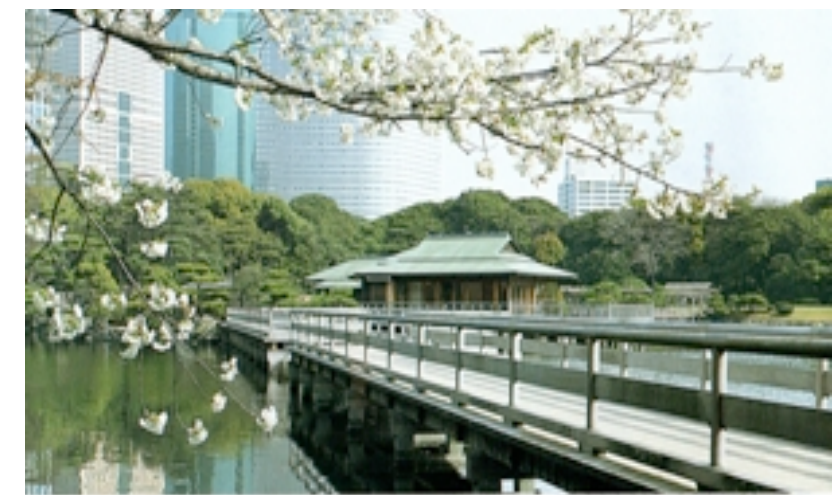

Fig. 1. Jardines de Hama-rikyu, Tokio

Imagen procedente de la página: http://www.yes-tokio.es/teien.php 


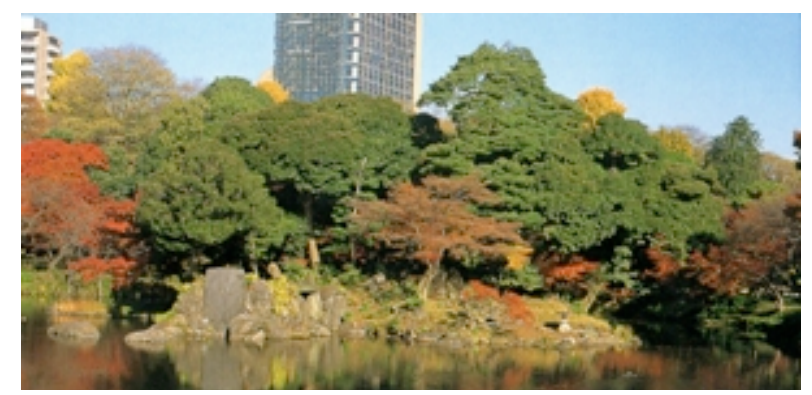

Fig. 2. Jardines de Hama-rikyu, Tokio

Imagen procedente de la página: http://www.yes-tokio.es/teien.php

En Europa hablaremos de urbes como Madrid que es una de las ciudades que poseen más jardines y espacios verdes y en las últimas décadas ha realizado numerosas incorporaciones de estas zonas a la vida de la ciudad, siendo galardonada en el 2010 con el premio Green Good Design en reconocimiento a sus iniciativas urbanísticas de carácter sostenible destacando las grandes zonas verdes de que dispone, tanto las ya existentes como el Retiro o La Casa de Campo y las recientemente incorporadas como Madrid Río, espacio del que más adelante hablaremos.

Como ejemplo de jardín inmerso en la ciudad de Madrid citaremos los de la Torre Picasso realizados por Leandro Silva Delgado, uno de los paisajistas más relevantes de la segunda mitad del siglo XX en España, en donde se integran perfectamente la plaza y su entorno. La vegetación está creada a una escala humana, lo que, frente a las monumentales construcciones verticales, introduce un elemento a escala del ciudadano en los accesos. En el nivel inferior se hicieron unos pequeños jardines geométricos y coloridos y hacen referencia a la idea de jardín cerrado y secreto, frente a la apertura de la gran plaza.

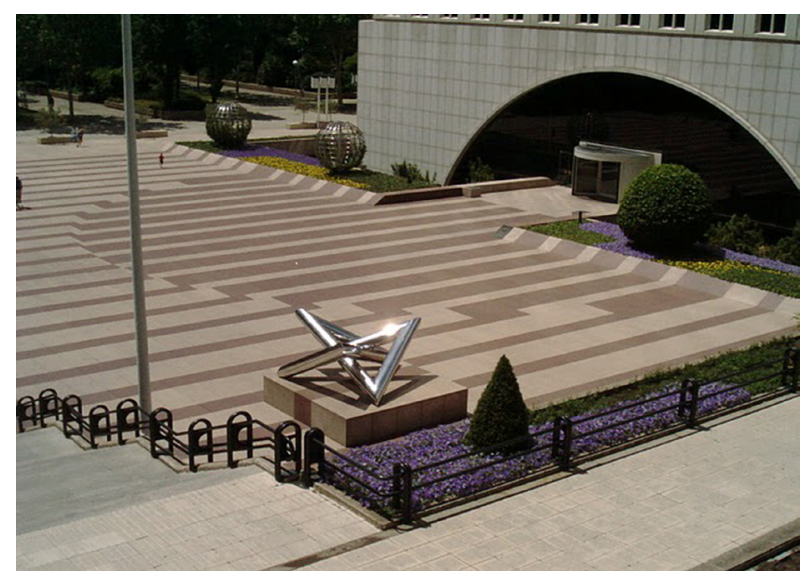

Fig. 3. Jardines de Torre Picasso Imagen procedente de la página: http://paisajelibre.blogspot.com 
Como antes mencionábamos, una de las zonas verdes más destacadas en esta ciudad es la realizada a orillas del río Manzanares denominada Madrid Río cuyas obras comenzaron en el 2007 y finalizaron en abril del 2011, habiéndose creado un espacio que ya forma parte del paisajismo contemporáneo de esta urbe.

Madrid Río se estructura en torno a nueve espacios: 6 grandes zonas ajardinadas, el Salón de los Pinos que es la columna vertebral de todo el parque, el bulevar de la Avenida de Portugal y la Huerta de la Partida. Se ha llevado a cabo una remodelación que ha permitido crear más de diez kilómetros para uso peatonal, por lo que hace posible para el ciudadano una mejor contemplación y disfrute de algunos de los tesoros urbanísticos que posee Madrid como la ermita de la Virgen del Puerto, construida por el arquitecto Pedro de Rivera en el siglo XVIII, El Puente del Rey, La Puerta del Rey, etc.

Para la buena conexión entre ambas orillas del Río Manzanares hay 33 puentes y pasarelas, algunos ya existentes que han sido remodelados y otros de nueva creación que pueden ser considerados como obras maestras de la arquitectura, como por ejemplo la pasarela de espirales y mallas realizada por Dominique Perrault de más de 200 metros de longitud formado por dos tramos de forma cónica, o espacios para el arte como el mosaico realizado por Daniel Canogar (figura 4) en la bóveda del Puente del Invernadero y que utilizó como modelos a ciudadanos anónimos de la ciudad.

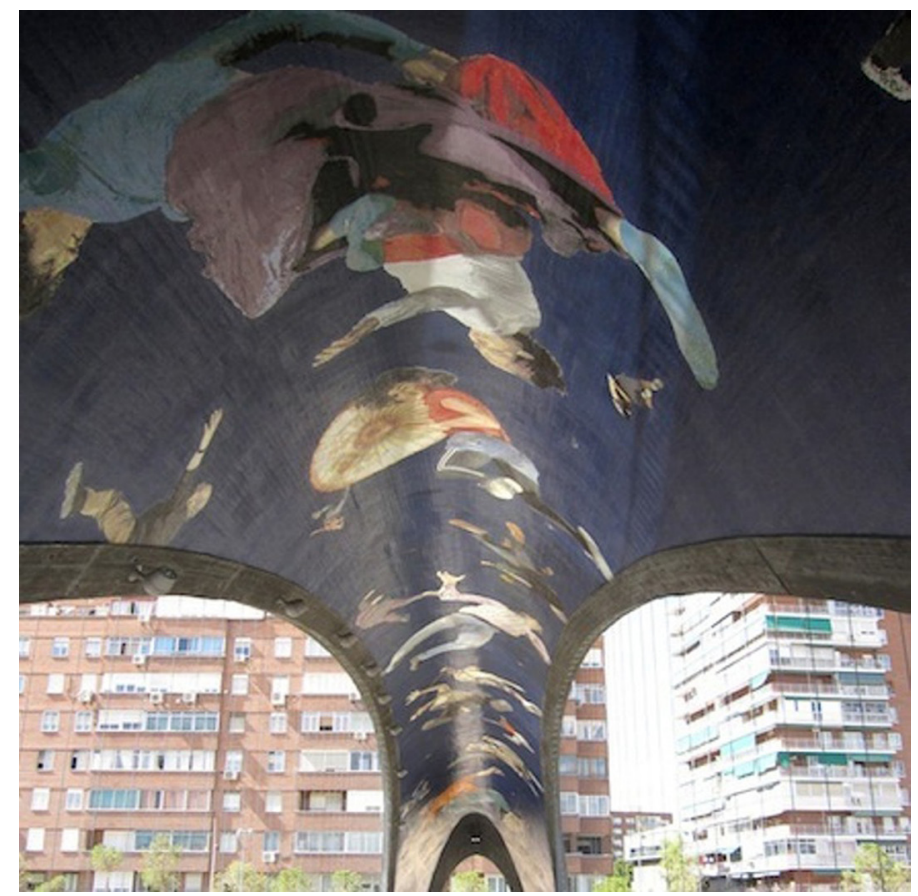

Fig. 4. Mosaico realizado por Daniel Canogar en la bóveda del Puente del Invernadero Imagen procedente de la página: www.madrid.es 
La construcción de estos espacios se corresponde tanto con las necesidades sociales como con las emocionales del hombre, están planificados como lugares de recreo para una de las zonas más pobladas de la ciudad.

Dado que el curso del río manzanares constituye el cordón umbilical de Madrid Río, el agua es uno de los elementos de mayor importancia habiéndose creado estanques fluviales y formidables fuentes como la de los jardines de Virgen del Puerto, además de haberse rehabilitado las ya existentes como la fuente monumental situada en la zona de La Casa de los Vargas.

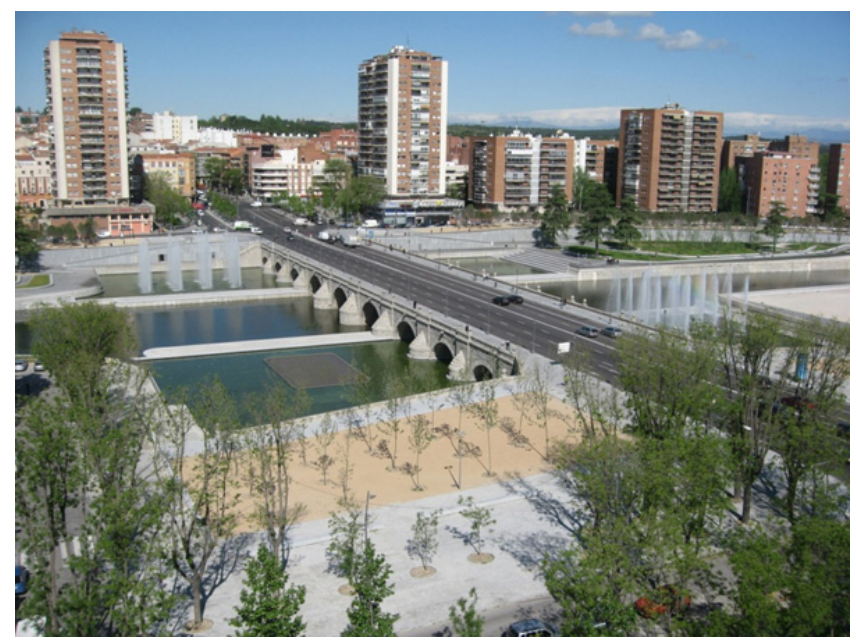

Fig. 5. Puente de Segovia

Imagen procedente de la página: www.madrid.es

\section{Jardines - Espacios verdes}

En el s. XX, la evolución de los jardines y parques tomó distintas direcciones, dominando sin duda los denominados parques de recreo y los espacios urbanos configurados, pasando a un segundo plano el concepto de los jardines románticos.

Como hemos mencionado en la introducción de este texto, la idea de zona verde que integra en el paisaje los diversos usos sociales y recreativos que reclama la población, no ha de confundirse con la esencia de lo que es un jardín, cuya finalidad principal es la de la búsqueda de la contemplación y satisfacción espiritual. Debe fomentarse el cuidado de los vergeles ya existentes sin que pierdan su esencia, e incluso restaurarlos cuando estos se encuentran en malas condiciones, pues son un diario existencial de las ciudades donde se encuentran.

Como ejemplo de correcto proceso de restauración de un jardín lo podemos poner en el Real Jardín Botánico de Madrid4 creado en el reinado de Carlos III en 1781, y que podríamos decir que supone para la ciencia de nuestro país una referencia tan importante como su vecino el Museo del Prado lo es para la pintura. Esta restauración fue llevada a cabo por el anteriormente citado Leandro Silva, que cuando la comenzó se encontró un jardín en condiciones de gran abandono, en donde los paseos casi no 
se podían ver porque la maleza lo invadía todo, pero la esencia del verdadero jardín se encontraba allí latente, esperando el momento en el que alguien lo volviera a descubrir y dar sentido, siempre bajo los parámetros del rigor, pues como hemos expuesto con anterioridad, el jardín es un elemento más del patrimonio cultural del hombre, ya que además de poder valorar su estética, es fruto del trabajo de un momento sobre un entorno y es reflejo de un tiempo y su cultura.

La buena conservación de un jardín histórico y su correcto mantenimiento deben ir unidos a la comprensión de sus sutiles mecanismos culturales. (Gómez Municio, J.A. 2002, p. 208)

\section{Conclusiones}

La reaparición de la apreciación del jardín es un importante símbolo que hace referencia a que las cosas en este siglo XXI pueden cambiar hacia una mayor valoración y armonía con el entorno que nos rodea. El hombre debe volver a dejarse fascinar por los mensajes que a lo largo de la historia nos han transmitido los jardines: relación armónica con el entorno.

Los jardines, como elementos vivos que son, se van transformando con el paso del tiempo pero si sus diseños están correctamente realizados, perdurarán a lo largo del tiempo convirtiéndose en auténticos monumentos históricos.

En la actualidad, parte importante de la estética de las urbes del s. XXI la conforman entre otros elementos los jardines y las zonas verdes, los cuales, además de cumplir una función estética e incluso terapéutica para el ciudadano, también ayudan a mejorar la calidad de vida de estos.

Si la idea de paisaje es un componente cultura importante en la historia del hombre, no lo es menos el concepto de jardín. Junto a este renacimiento de los vergeles, el urbanismo contemporáneo ha potenciado la aparición abundante de áreas verdes, las que aún siendo muy necesarias pues además de cumplir una función estética y lúdica, tienen un papel importante como pulmones de las ciudades, deben de ser concebidas con un mayor equilibrio relacionado con el urbanismo y cuya funcionalidad no debe sustituir a la del jardín, manteniendo un criterio diferenciado aunque complementario con éste.

La integración adecuada de los jardines en las ciudades es de gran importancia tanto para la estética de las urbes como para el bienestar del hombre que las habita. Si los espacios verdes son mal diseñados, no corresponden a las necesidades de los ciudadanos, ni se adaptan a su entorno ni a las funciones que deben cumplir, como por ejemplo la socialización, provocando así una falta de valoración y degradación del espacio. 


\section{Referencias}

Gómez Municio, J. A. (2002). El universo en el jardín. Paisaje y arte en la obra de Leandro Silva. Castilla y León: Consejería de Medio Ambiente y Ordenación del Territorio.

S.G.T. Ministerio de Medio Ambiente, (2007). Convenio europeo del paisaje: Textos y comentarios. Madrid: Ministerio de Medio Ambiente.

\section{Notas}

1. Artículo 1. A los efectos de la presente Convención se consideran "patrimonio cultural":

"[...] los conjuntos: grupos de construcciones, aisladas o reunidas, cuya arquitectura, unidad e integración en el paisaje les dé un valor universal excepcional desde el punto de vista de la historia, del arte o de la ciencia.

Cf. Normativa relativa al Plan de Paisajes Culturales. Recuperado el 4 de septiembre de 2011 de http://www.mcu.es/ patrimonio

2. Carta de Florencia adoptada por el Comité Internacional de Jardines Históricos ICOMOSIFLA en diciembre de 1982 relativa a la salvaguardia de los jardines históricos y como complemento a la Carta de Venecia. http://www.international.icomos.org (30/08/2011).

3. El jardín japonés tiene su origen en el período Nara (710-790 d.C.) y su génesis estaba basada en la necesidad de crear un espacio de meditación para el hombre. Los elementos de estos jardines son únicamente objetos naturales que mediante una cuidada colocación hacen que el jardín estimule los sentidos y sea un espacio para la contemplación.

4. A mediados del XIX el Real Jardín Botánico fue modificado, su diseño neoclásico de Sabatini y Villanueva fue sustituido por un trazado irregular acercándolo a la idea de jardín inglés. 